\title{
25. REMANENT MAGNETIZATION OF SEDIMENTS UNDERGOING DEFORMATION IN THE BARBADOS ACCRETIONARY PRISM: ODP LEG 110 1
}

\author{
M. W. Hounslow, ${ }^{2,3}$ P. A. Bootes, ${ }^{2}$ and G. Whyman ${ }^{2}$
}

\begin{abstract}
The depositional remanent magnetization of samples collected on ODP Leg 110 is partially overprinted by a magnetization acquired in the Brunhes and an enigmatic coring or sampling remanence. The overprint acquired in the Brunhes may be a result of deformation related to grain fabric modification or to diagenetic alteration of the remanence-carrying titanomagnetite, derived from volcanic ash. In some samples from Hole 671B the primary remanence is partially retained, leading to a polarity stratigraphy that correlates with part of the Pleistocene-Pliocene sequence. However, the polarity stratigraphy is of too poor a quality to enable any meaningful time constraints. In the section with steeply dipping bedding in Hole 671B the anisotropy of magnetic susceptibility can be used to correct the remanence inclination because of the unique relationship between geomagnetic north and the $\mathrm{E}-\mathrm{W}$ compression direction at this site.
\end{abstract}

\section{INTRODUCTION}

A study of the remanent magnetization of sediments can yield important information about sediment ages, through the use of a polarity stratigraphy, and can also be used to determine the geographic orientation of cores and samples. In tectonically deformed sediments a major problem in attempting to use the remanent magnetization for these purposes is the fabric disruption and the folding that occurs in such environments. Folding with no accompanying grain fabric modification (passive limb rotation of the remanence), has frequently been assumed in terrains of low strain, where unfolding techniques have been widely used in paleomagnetic studies (Facer, 1983). These paleomagnetic tests assume that the remanent magnetization direction retains its original angular relationship with the bedding plane, and it is therefore easy to correct remanence directions from dipping beds using a knowledge of the sample/bedding plane/ fold relationship.

More detailed studies of remanence directions in tectonites indicate that the folding mechanism and the accompanying grain fabric modification can strongly influence whether the remanence retains its original angular relationship with the bedding (Pluijm, 1987; Cogne, 1987). Strain-induced rotation of the remanent magnetization away from the primary magnetization direction has been demonstrated by Ozima (1980) in Ni-Fe aggregates, and Blow and Hamilton (1978) in sediments. From simple models of grain fabric development during progressive strain the remanent magnetization vector is expected to deflect toward the direction of maximum extension. Some authors claim to be able to correct the remanence direction for this grain rotation, given a knowledge of the strain ellipsoid and assuming that the remanent magnetization behaves as a passive marker (Cogne, 1987; Cogne and Perroud, 1987). Such a simplistic model of fabric modification may not be generally applicable to low grade tectonites, particularly considering the many variables involved in grain orientation and recrystallization under stress (Hobbs et al., 1976). Deep-sea sediments may be simple systems in this respect because of the lack of significant diagen-

\footnotetext{
${ }^{1}$ Moore, J. C., Mascle, A., et al., 1990. Proc. ODP, Sci. Results, 110: College Station, TX (Ocean Drilling Program).

2 Department of Geology, Sheffield University, Sheffield, S3 7HF, U.K.

3 Currently at: School of Environmental Sciences, University of East Anglia, Norwich, NR4 7TJ, U.K.
}

etic crystallization of the remanence carrying phases. However, compaction induced shallowing of the remanence, expected from Blow and Hamilton's (1978) work, has not been widely reported from deep-sea sediments, although Kent and Spariosu (1983) suggested this shallowing occurred in some Caribbean cores they examined.

The purpose of this study was to examine the remanent magnetization of the deformed sediments cored on ODP Leg 110, for use in core orientation and polarity stratigraphy considering the expected disruptive influences from the deformation on the remanence signature. Paleomagnetic samples were collected from three Holes, 671B, 673A, and 674A. These same samples were also used in the companion study of the anisotropy of magnetic susceptibility (Hounslow, this volume).

\section{MEASUREMENT TECHNIQUES AND ANALYSIS}

In the less consolidated parts of the core, samples were taken by pressing plastic cuboid sample holders (internal dimensions $2.1 \times 2.1 \times 1.5 \mathrm{~cm}$ ) into the sediment with the fiducial arrow pointing up-core. In the more indurated cores a sample was cut by a stainless steel knife to fit inside the holders. Parts of the cores with obvious drilling-produced structures were avoided, and in biscuited XCB cores, samples were taken only from drilling biscuits that had parallel sides indicating that they had suffered little if any rotation about a horizontal axis.

The remanent magnetization was measured using a MOLSPIN fluxgate spinner magnetometer (sensitivity about $\mathbf{0 . 0 2}$ $\mathrm{mA} / \mathrm{m}$ ) on both the JOIDES Resolution and in the laboratory at Sheffield. The samples were subjected to AF demagnetization using either the shipboard Schonstedt three-axis, non-tumbling demagnetizer or a MOLSPIN tumbling demagnetizer at Sheffield. The demagnetization data was analyzed using orthogonal vector diagrams and stereographic projections. A high proportion of the samples were demagnetized until either a stable component was apparent or the scatter in direction was too great to be meaningful. A number of samples were demagnetized at a single optimum level based on the behavior of adjacent similar lithology samples. Samples from the Cores $110-674 \mathrm{~A}-15 \mathrm{X}$ to $-48 \mathrm{X}$ and $110-671 \mathrm{~B}-42 \mathrm{X}$ to $-72 \mathrm{X}$ were stored in a field free space at least $48 \mathrm{hr}$ prior to demagnetization to reduce viscous components of magnetization to a minimum. Samples with a high proportion of low-coercivity material tended to acquire spurious magnetizations from the demagnetizers both on board ship and at Sheffield, which may have contributed considerably in some cases to the scatter during demagnetization. 
In progressively demagnetized samples the reliability of the direction of the stable high coercivity component was grouped into four categories of decreasing reliability:

1. The direction was stable, producing a linear trajectory on an orthogonal vector diagram (after removal of the low-coercivity component).

2. The demagnetization path indicated on an orthogonal vector diagram was strongly curved (progressive planar movement on a stereographic projection), indicating that a directionally stable high-coercivity component may not have been reached; or that the scatter was relatively large about a stable end point.

3. The uncertainty in defining the direction of the high-coercivity component was larger than in category 2 .

4. The scatter during demagnetization was so large as to not define a characteristic direction with any certainty, or the samples natural remanent magnetization (NRM) intensity was below $0.1 \mathrm{~mA} / \mathrm{m}$. In these cases the NRM direction was used and assigned a reliability category of 4 .

\section{MAGNETIC PROPERTIES}

The NRM intensity of the Pleistocene to middle Miocene sediments was generally above $10 \mathrm{~mA} / \mathrm{m}$ and the volume susceptibility above $80 \times 10^{-5}$ SI (Figs 1, 6, and 7). Sediments older than the middle Miocene generally have values lower than these. The exceptions to this observation are some parts of the sequence in Hole 674A (310-350 mbsf and 405-450 mbsf; Fig. $7)$, which are assumed, on lithologic grounds, to be Oligocene in age and have a significant volcanic ash content (Mascle, Moore et al., 1988). The median destructive field (MDF) is generally between 5 and $12 \mathrm{mT}$ in the Pleistocene to middle Miocene sediments, with a higher proportion greater than $10 \mathrm{mT}$ in the sequence older than middle Miocene. Magnetically shielding the samples prior to demagnetization may have slightly raised the MDF because of the reduction in the proportion of viscous components. The low coercivity of the remanent magnetization carrying phase is typical of multidomain titanomagnetite, although the stable intensity of some samples from the Oligocene and Eocene suggests a different ferromagnetic mineralogy.

Polished sections of ash layers from the Pleistocene and Pliocene of Hole 676A, and representative samples from the Pleistocene and Pliocene from Hole 671B, were examined using oil-immersion reflection microscopy. These samples are assumed to be representative of the magnetic mineralogy in the Pleistocene to middle Miocene because of the consistent heavy mineral assemblages over this interval (Ogawa, pers. commun., 1986). Euhedral to anhedral homogeneous titanomagnetite grains are on average less than $10 \mu \mathrm{m}$, with individual grains up to $200 \mu \mathrm{m}$ in size. A minority of these grains show oxidation to titanomaghemite and hematite. The oxidation to titanomaghemite has a patchy

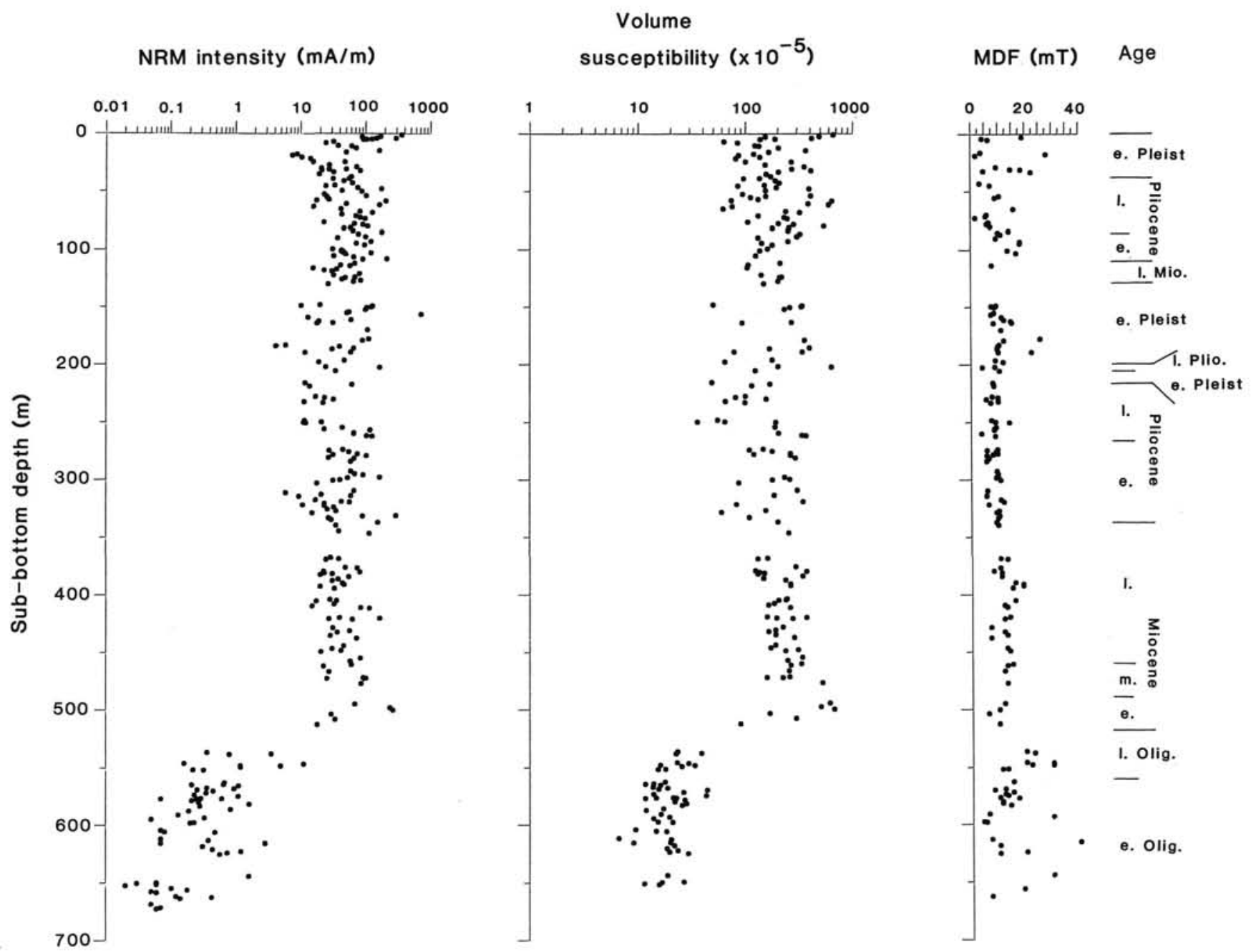

Figure 1. Natural remanent magnetization intensity, volume susceptibility, and median destructive field (MDF) measurements for samples from Hole 671B. Age is based on bio- and lithostratigraphy. 
appearance not following any microstructural features, with alteration domains generally less than $10 \mu \mathrm{m}$ (cf., Dimanche and Bartholome, 1976; Haggerty, 1976). Hematite in altered grains is generally present around grain edges and cracks in the grain periphery. A small proportion of titanomagnetite/ilmenite intergrowths are also present being indicative of normal igneous high temperature oxidation textures (Haggerty, 1976). Titanomagnetite grains $(<10 \mu \mathrm{m})$ are also very common as inclusions in other grains.

Equally abundant as unaltered titanomagnetites in some samples are grains with a porous texture and strong orange-to-reddish internal reflections. These appear to be composed of a fine-grained ( $<5 \mu \mathrm{m}$ in size) intergrowth of $\mathrm{TiO}_{2}$ phases with small amounts of possibly hematite or goethite, and are probably similar to the intermediate $\mathrm{TiO}_{2}$ oxidation mineralogy described by Dimanche and Bartholome (1976). These textures indicate oxidation from an original homogeneous titanomagnetite, and probably represent the end product of the initial titanomagnetite oxidation textures described above. These features are thought to result from the diagenetic removal of $\mathrm{Fe}$ from the original titanomagnetite in the volcanic ash, via the intermediate alteration products titanomaghemite and hematite (Karlin and Levi, 1983; Morad and Aldahan, 1986).

\section{RESULTS}

Most samples contain two components of magnetization, with some possessing three and others only one component. Samples from the uppermost $10 \mathrm{~m}$ of sediment generally have only a single component of magnetization and samples with multiple components have generally strongly overlapping coercivity spectra. A typical demagnetization field at which the high-coercivity component is sufficiently directionally stable is $18-25 \mathrm{mT}$, although this is above $60 \mathrm{mT}$ or as low as $5 \mathrm{mT}$ in some samples. A large majority of samples have a near-vertical, positive, low-coercivity component.

\section{Hole 671B}

\section{Overthrust Sequence}

The high-coercivity component inclinations for Cores 110671B-1H to $-55 \mathrm{X}$ show a broad spread of values centered near the $27^{\circ}$ expected for the present geomagnetic field, with abundant steeper positive values (Fig. 2). However, the relative lack of negative inclinations suggests that some kind of remagnetization process is operative. Many samples from the APC-cored section (Cores 110-671B-1H to $-10 \mathrm{H}$ ) do not show the expected $180^{\circ}$ change in the declination that accompanies a change in the inclination from positive to negative (Fig. 3). We interpret these features to be a result of a magnetic overprint with a positive component that could be either close to the present-day geomagnetic field or steeper in inclination.

The declinations of Cores 110-671B-1H to $-6 \mathrm{H}$ show good within-core repeatability, in comparison to cores below, with the polarity stratigraphy based on the inclinations showing a rather poor correlation to the magnetic polarity time scale (MPTS, Berggren et al., 1985). The poor correlation in Cores 110-671B$2 \mathrm{H}$ and $-3 \mathrm{H}$ is probably a result of the complicated stratigraphy suggested by the susceptibility stratigraphy in these cores (Hounslow, this volume). The poor correlation of the Eastman-Whipstock multishot orientation device north and the paleomagnetic north determined for the cores is apparently quite common with this device (Barton and Bloemendal, 1986; Fig. 3).
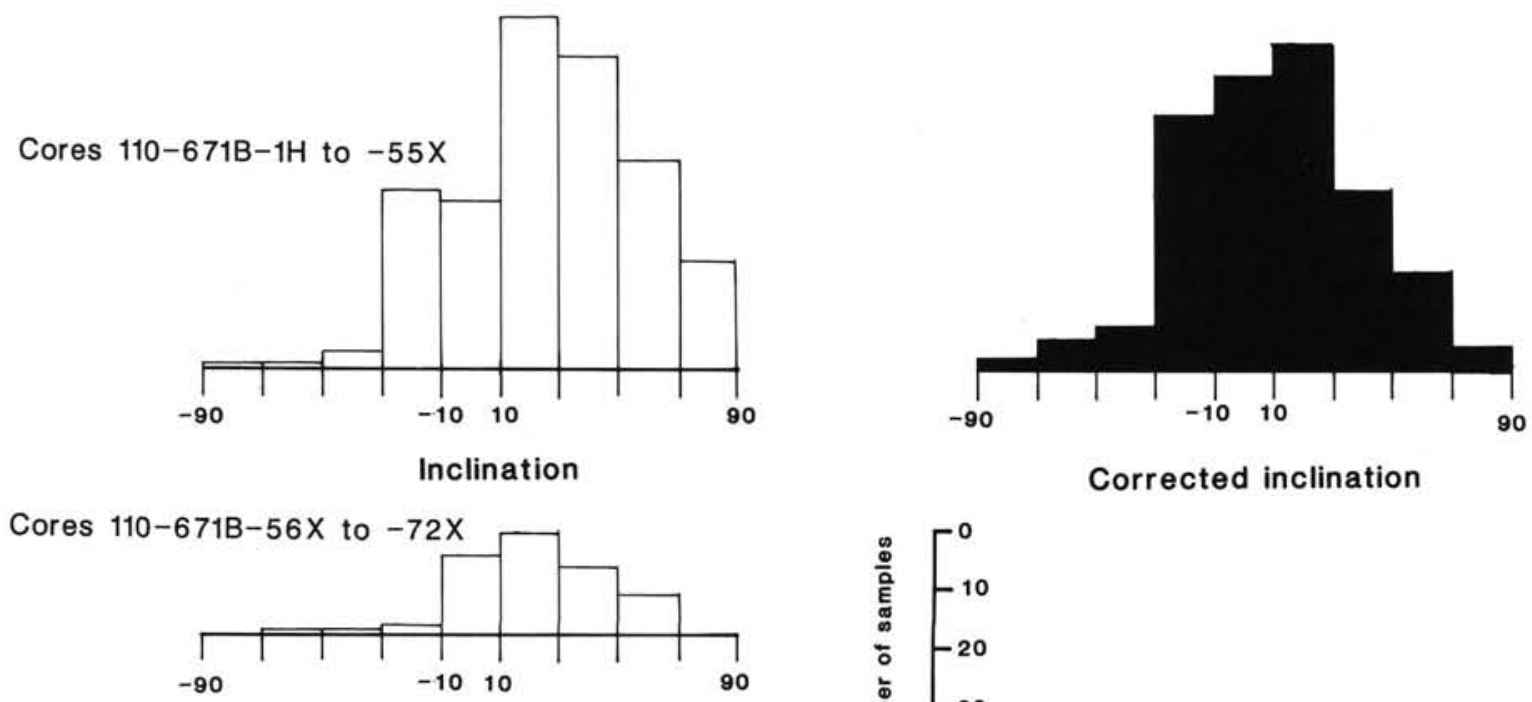

Inclination

Corrected inclination

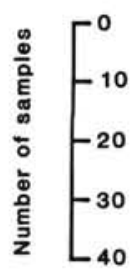

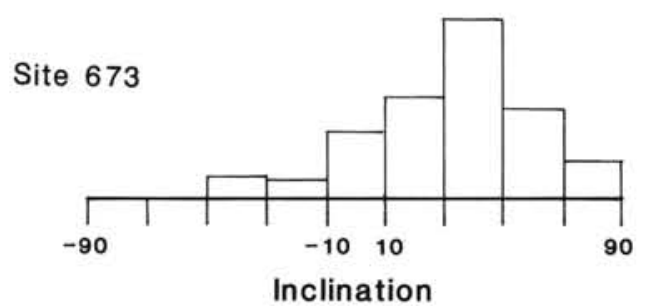

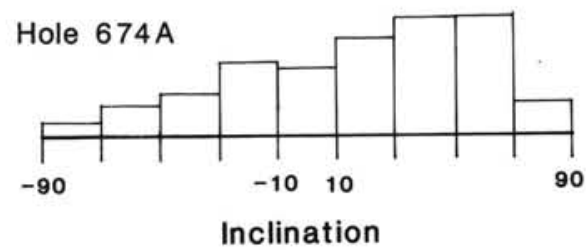

Figure 2. Histograms of the high-coercivity component inclinations for samples from Sites 671, 673, and 674. 

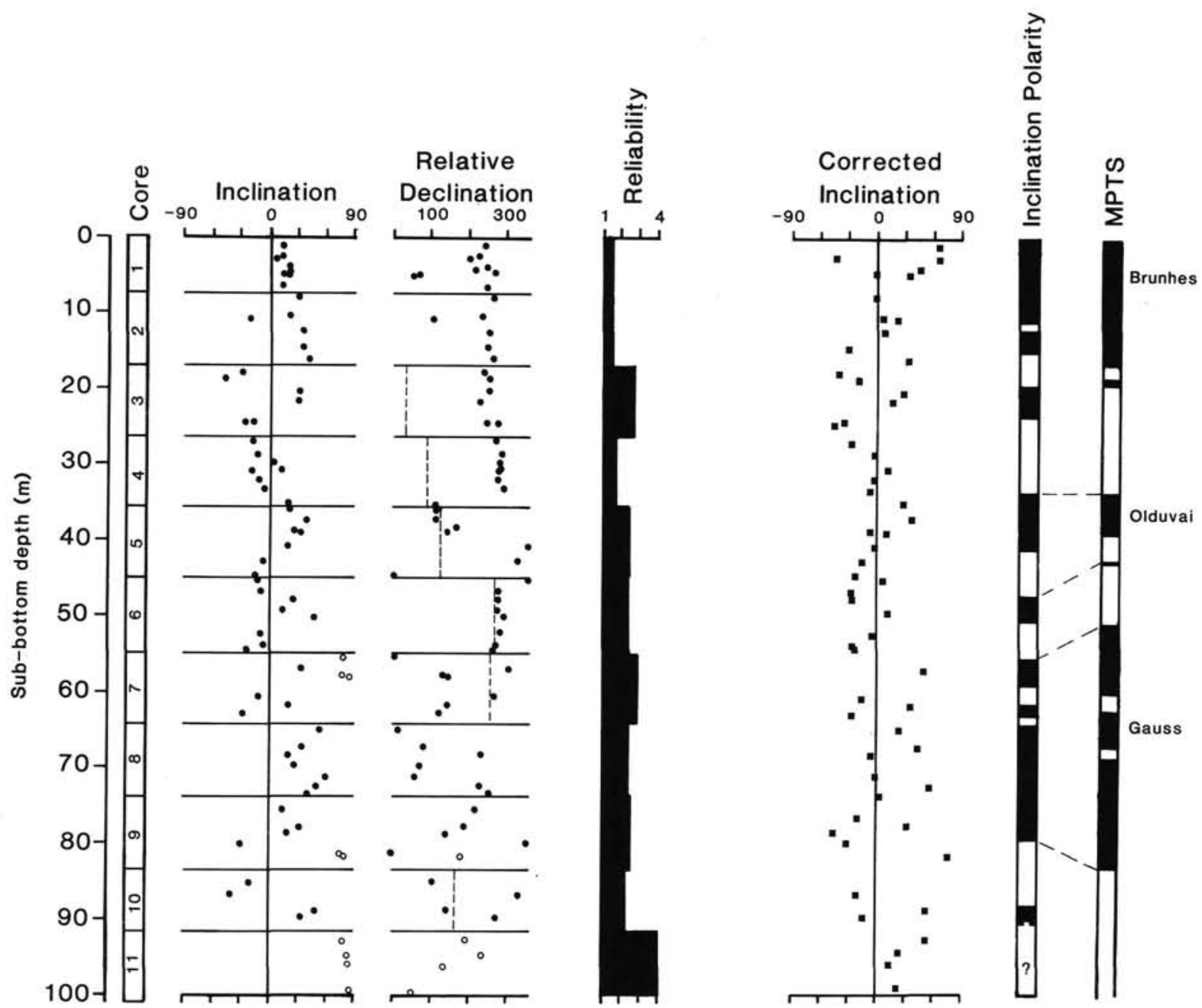

Figure 3. Remanence data for the top $100 \mathrm{~m}$ of Hole $671 \mathrm{~B}$, with the interpreted polarity and its correlation to the magnetic polarity time scale of Berggren et al. (1985), based on the nannofossil data of Clark (this volume). Open symbols represent NRM data. Indeterminate polarity is indicated by a ? and a broken upper and lower boundary. North, as read on the multishot orientation device, is marked with a dashed line on the relative declination plot. The "corrected inclination" values are derived from the sample inclination values by way of a correction applied with the anisotropy of magnetic susceptibility values (see text for details).

Samples from Cores 110-671B-12X to $-56 \mathrm{X}$ have dominantly positive inclinations, which are considerably steeper than expected. The inclination distribution reflects the observed bedding dips, with more negative inclinations in areas of shallow dips (Fig. 4). In the section between 100 mbsf and the major thrust fault at $128 \mathrm{mbsf}$, several samples have negative inclinations that may correspond to some of the expected negative polarities in this interval (Fig. 4). In the section below $128 \mathrm{mbsf}$ it is clear that the measured inclinations do not match the MPTS, even in areas of shallow bedding dip.

If we consider that the folding in this sequence is about a horizontal N-S direction (Hounslow, this volume), and the remanent magnetization direction retains its original angular relationship with the bedding, then progressively higher angles of tilt will produce lower inclinations closer to zero, distributed either side of north. To produce the inclination pattern in Hole 671B below 128 mbsf (Fig. 4) using this model, we have to invoke a positive, perhaps steeply dipping overprint on the primary remanence that is not resolvable due to coercivity overlap. Evidence for a strong overlap of coercivity is found in the frequently curved nature of the orthogonal vector plots. Such an overprint could include a magnetization acquired in the Brunhes, perhaps through the titanomagnetite oxidation and the extensive volcanic ash alteration that has occurred in these sediments. This overprint also may be aided by the tectonic fabric disruption of these porous sediments. However, the frequently steeper than expected inclinations in some samples points also to a positive component steeper than the present geomagnetic field.

There are two possible origins for this steeply dipping component:

1. A drilling- or core handling-induced remanence. Sub-vertical magnetization acquired either while coring or in subsequent handling has been suggested in a number of studies of deep-sea cores (Barton and Bloemendal, 1986). It is by no means clear by what mechanism such a remanence could arise.

2. A tectonic strain-induced rotation of the remanent magnetization. As outlined above, tectonic shortening will induce a deflection of the remanent magnetization toward the extension direction that is vertical based on the evidence of Hounslow (this volume). It is not clear how such a fabric modification 


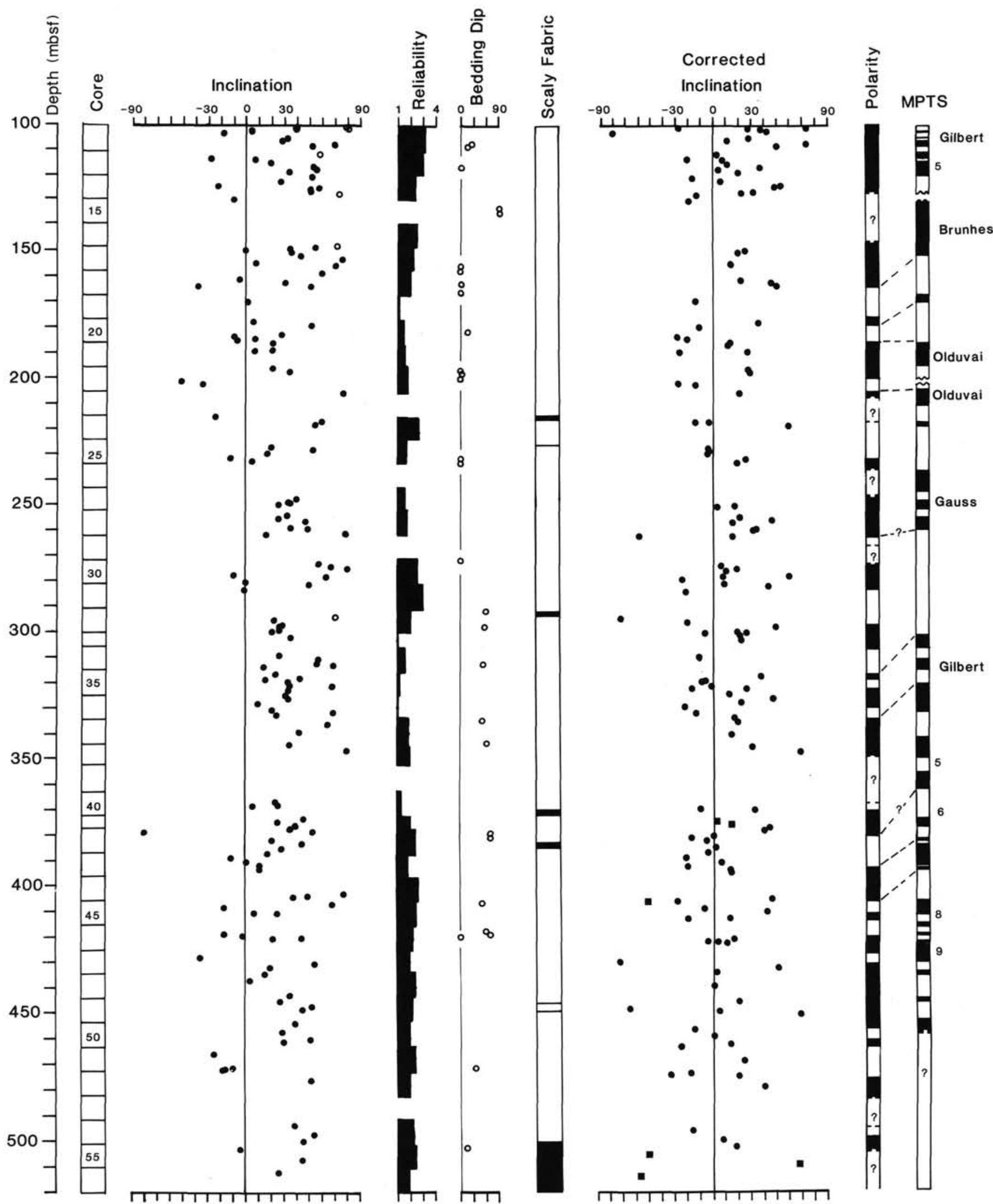

Figure 4. Remanence data and structural information for the interval 100-500 mbsf of Hole 671B. The "corrected inclination" values are derived from the sample inclination values by way of a correction applied with the anisotropy of magnetic susceptibility values (see text for details). The polarity interpretation is based on the "corrected inclination" values. The magnetic polarity time scale is based on the biostratigraphy. 
would manifest itself in its response to demagnetization; whether different titanomagnetite grain sizes would respond in different ways to the strain.

Notably, Wilson (1984) does not identify any significant subvertical component in the Leg 78A cores from the Barbados Ridge, and the inclination values he measured show scattered values centered about zero. In addition, Niitsuma (1981) and Niitsuma (1986) do not identify over-steepened inclinations in the Central American Trench, the Nankai Trough, or the Japan Trench accretionary prisms, where a strain-induced remanent magnetization rotation might be expected. The lack of strain-induced magnetic grain rotation in similar accretionary prism settings suggests that the first of these proposals may be more likely. In addition, Wilson's (1984) data together with these Leg 110 results suggest that the coring and sampling procedure on the JOIDES Resolution is more prone to remagnetizing the sediment from the Barbados Ridge than the data from the Glomar Challanger. The generally unstable nature of the remanance from the Barbados Ridge may be due to the abundance of multidomain, low-coercivity titanomagnetite.

Niitsuma (1981) and Niitsuma (1986) have used the coincidence of samples and bedding plane information to apply tilt corrections (assuming passive limb rotation of the remanent magnetization), to improve the magnetostratigraphic information. This would have been wholly inadequate for samples from Leg 110 because of the infrequency of such planes in most of the sedimentary sequence. Before the anisotropy of magnetic susceptibility measurements had been undertaken (Hounslow, this volume), it was thought that this measurement might reflect the orientation of the bedding plane, and therefore it would be possible to use it instead to produce an improved assessment of the polarity stratigraphy. This is achieved by determining the angle between the plane perpendicular to the minimum susceptibility $\left(K_{\min }\right)$ direction and the remanence inclination. Assuming only passive limb rotation and a primary susceptibility anisotropy, this angle should represent the original remanent magnetization inclination. However, considering the susceptibility anisotropy data presented by Hounslow (this volume) the bedding plane in these sediments cannot be reliably determined with this technique. Nevertheless, as a simple trial the above angle was calculated; hereafter it is referred to as the "corrected inclination" (Figs. 3 and 4). The corrected inclination has a more even distribution of values, with more negative inclinations than the in-situ values. In addition, using these values for the part of the sequence below the major thrust at 128 mbsf produces a polarity stratigraphy that is surprisingly similar to the MPTS. To try to explain the apparent success of this calculation we have to consider the bedding plane dips and the susceptibility anisotropy relative to geographic north. In Hole 671B below $128 \mathrm{mbsf}$ the susceptibility anisotropy represents the combination of the sedimentary fabric and a superimposed tectonic fabric, which together produce E-W horizontal $K_{\min }$ and N-S horizontal $K_{\max }$ (Hounslow, this volume).

It is clear why the calculation of the corrected inclination in the sections with steeply dipping bedding has given rise to shallower values and a match to the MPTS. A plane perpendicular to the $K_{\min }$ direction passing through north will bisect the primary remanent magnetization directions (assuming passive limb rotation about a N-S fold axis). The polarity of the corrected inclination depends upon which limb of the fold was sampled. If these assumptions are correct then the polarity interpretation implies that the bedding in Cores 110-671B-32X to $-46 \mathrm{X}$ is dipping in a westerly direction. The discrepancy in Cores 110-671B$27 \mathrm{X}$ to $-30 \mathrm{X}$ may be due to short repeated intervals (Hounslow, this volume)
Applying these assumptions to the case of horizontal bedding, such a calculation is not likely to improve the inclination, which nevertheless it apparently does, for the interval from Core $110-671 \mathrm{~B}-17 \mathrm{X}$ to $-30 \mathrm{X}$, but not $110-671 \mathrm{~B}-1 \mathrm{H}$ to $-11 \mathrm{X}$. Why these calculations apparently improve the inclination values cannot be explained and therefore the interpretation should be treated with considerable caution. This technique only works at this site because of the E-W shortening; compression about another axis would not produce the same result.

\section{Underthrust Sequence}

The remanent magnetization data for samples from the Oligocene section below the déecollement horizon have dominantly positive inclinations with a median between $10^{\circ}$ and $30^{\circ}$ (Fig. $5)$. There is no correlation with the MPTS, suggesting an extensive secondary overprint of the primary remanent magnetization, which has probably occurred in the recent geomagnetic field. It is not clear what caused this remagnetization, whether by mineral alteration or growth or perhaps fabric modification caused by plate collision. The Eocene sediments measured by Wilson (1984) at the oceanic reference Site 543 were also extensively remagnetized, but by a negative overprint.

\section{Sites 673 and 674}

The inclinations at these two sites are dominated by positive values steeper than the present geomagnetic field and no correlation with the MPTS even for the Pliocene to Pleistocene slope deposits (Figs 6b, 7, 8, and 9). The remanent magnetization at these sites is probably strongly influenced by an overprint in the Bruhnes, and the steep component that was indicated in the results for Hole 671B. Nevertheless, the presence of some samples with negative high-coercivity components in Cores 110-674A$38 \mathrm{X}$ to $-44 \mathrm{X}$ (early Oligocene age), point to the preservation of an earlier remanence. The assumed original polarity (based on the biostratigraphy) of this sequence for a N-S fold axis would be normal. This implies that the negative values represent either a previous syn-folding magnetization or that the assumption about the fold axes is incorrect.

\section{REMANENCE DATA FOR CORE ORIENTATION}

The second objective of this work was to show that remanence data from the samples collected on Leg 110 can be used to orient cores. There are several lines of evidence that suggest this assumption is correct, even in severely deformed sediments:

1. A polarity stratigraphy is preserved in the upper parts of Hole $671 \mathrm{~B}$, and the internally consistent pattern of oriented susceptibility anisotropy data (Hounslow, this volume) in the overthrust sequence suggests that the remanence reflects the geomagnetic field.

2. The interpretation of the remanence data is consistent with a partial overprint acquired during the Brunhes, although there is evidence for the preservation of some remanence acquired prior to the most recent folding in Hole 674A. Hounslow (this volume) showed that in those parts of the sequence from Hole $674 \mathrm{~A}$ corresponding to the out-of-sequence faults the orientation of the susceptibility anisotropy axes by the NRM direction produced a better clustering than when using the high-coercivity component. The structural interpretation of these faults being the most recently active ones indicates clearly that processes in these zones are producing recent remagnetization of the low-coercivity phases.

The correct direction of geomagnetic north is less certain with this data because it is not always clear whether the recovered remanence points northward or southward. This is especially so in parts of the sequence that retain some pre-folding 


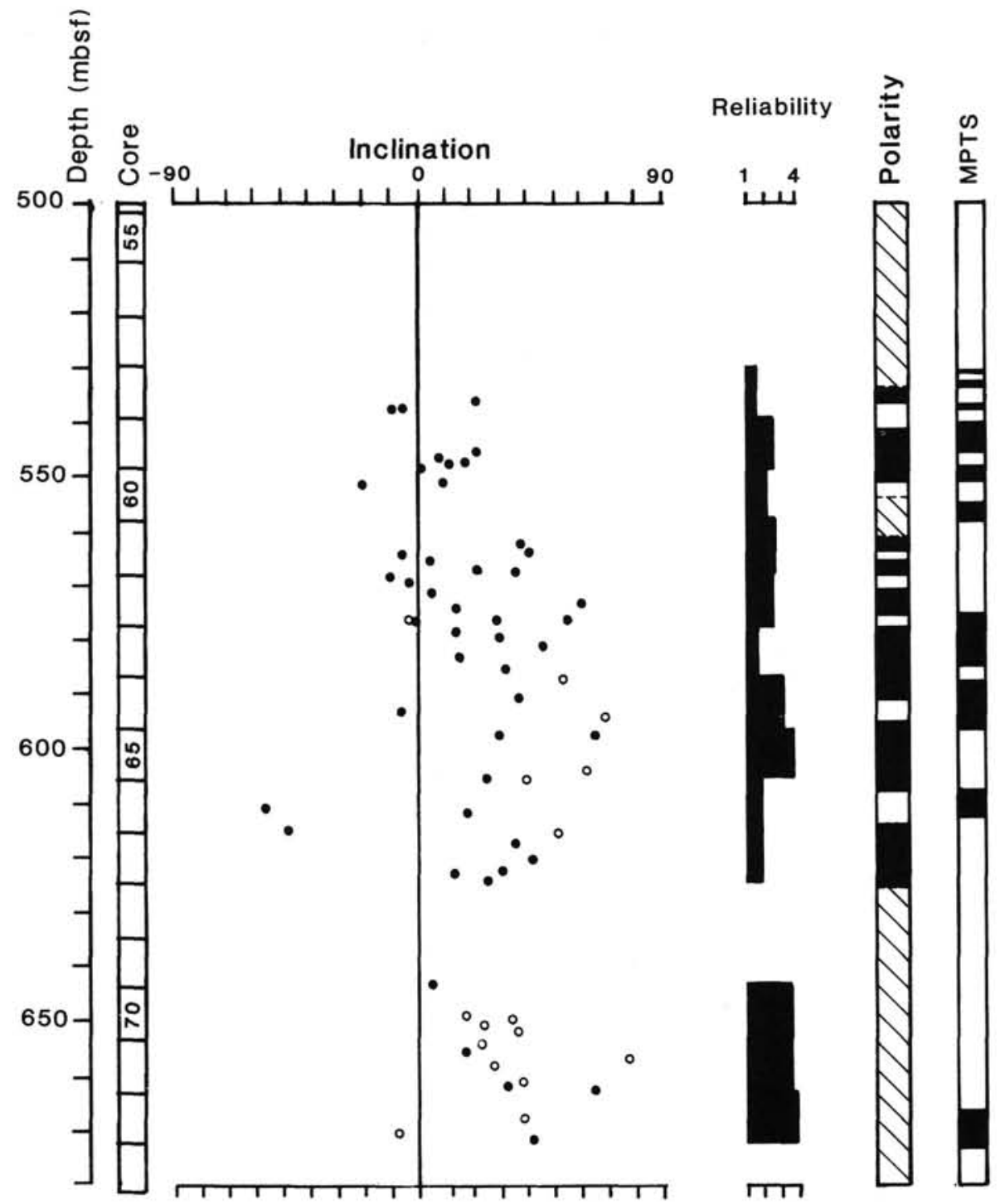

Figure 5. Remanence inclination values for the underthrust sequence of Hole 671B. Hatchured pattern indicates indeterminate polarity. The magnetic polarity time scale is that expected based on the biostratigraphy. No correlation with the MPTS has been attempted.

magnetization, as suggested for parts of Sites 673 and 674 . However, the interpretation of a strong recent remagnetization in the Brunhes epoch implies that the recovered remanence directions predominantly point northward. The folding about a $\mathrm{N}-\mathrm{S}$ axis of a remanence that preserves the pre-folding inclination/horizontal relationship will not unduly affect the correct orientation of samples, but may introduce a bimodal scatter about the N-S direction. Folding about a different axis may not preserve this relationship.

\section{CONCLUSIONS}

The remanent magnetization of samples collected on ODP Leg 110 from the Barbados accretionary prism is influenced by an enigmatic coring/sampling remanence. Some of the original primary remanence is preserved in these sediments, but it appears to be overprinted by a magnetization acquired in the Brunhes epoch.

The use of polarity stratigraphy in sediments from the Barbados accretionary prism for defining a stratigraphic frame- work is severely limited partly because of the lack of bedding plane control, although the record for the first $100 \mathrm{~m}$ of Hole $671 \mathrm{~B}$ does preserve a polarity sequence that is consistent with the MPTS, although of poor quality.

The behavior of the remanent magnetization in these sediments is largely incompatible with Cogne and Perroud's (1987) model of remanence evolution under stress, but is more strongly influenced by later remagnetization events. This study and work by Niitsuma $(1981,1986)$ from the Middle American Trench, the Nankai Trough, and the Japan Trench suggest that the remanent magnetization retains its original bedding plane relationship but is prone to remagnetizations in the present geomagnetic field. This remagnetization may be a result of the porosity being in excess of $50 \%$, leading to incomplete locking of the remanence carriers into the grain fabric, so that tectonically induced grain movement leads to remagnetizations in the geomagnetic field. The remagnetization may be aided in the case of the Barbados accretionary prism by the extensive alteration of volcanic ash, which is the dominant source of remanence-carrying minerals. 

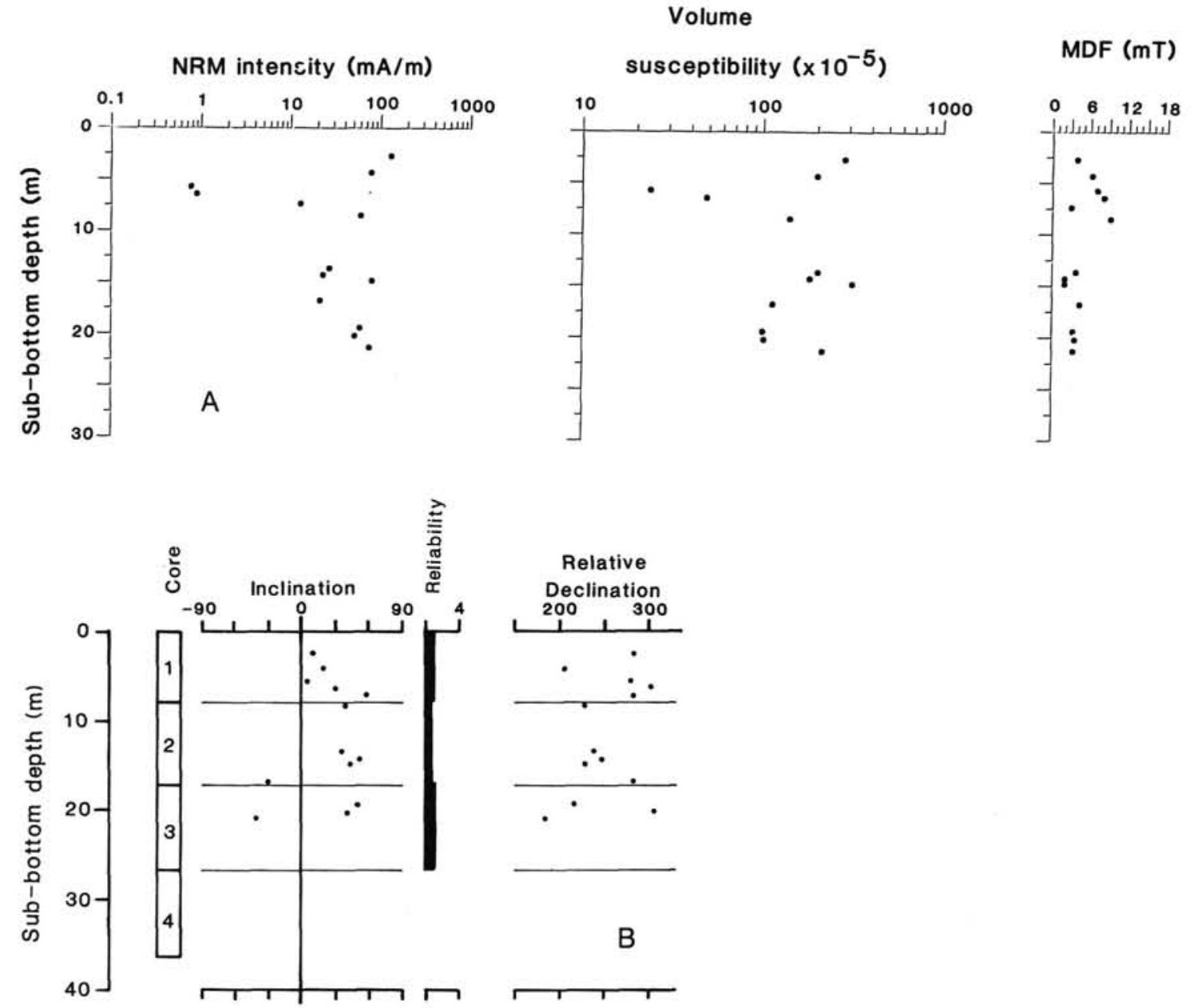

Figure 6. A. NRM intensity, volume susceptibility, and median destructive field for Hole 673A. B. Directional remanence data for Hole $673 \mathrm{~A}$.

Clearly, remagnetization is not a problem if the purpose of the work is to orient cores; in fact, it is an advantage, as it reduces any complicating effects caused by folding or grain fabric rotation that are not easy to resolve. Provided that remagnetization can be demonstrated, cores can be successsfully oriented even in severely deformed deep-sea sediments, leading to a more complete picture of the structural relationships in accretionary prisms.

\section{REFERENCES}

Barton, C. E., and Bloemendal, J., 1986. Paleomagnetism of sediments collected during Leg 90, Southwest Pacific. In Kennett, J. P., von der Borch, C. C., et al., Init. Repts. DSDP, 90: Washington (U.S. Govt. Printing Office), 1273-1316.

Berggren, W. A., Kent, D. V., and Couvering, J. A., 1985. The Neogene, Part 2. Neogene geochronology and chronostratigraphy. In Snelling, N.J. (Ed.), The Geochronology of the Geologic Record. Mem. Geol. Soc. London, 10:211-260.

Blow, R. A., and Hamilton, N., 1978. Effect of compaction on the acquisition of a detrital remanent magnetisation in fine-grained sediments. Geophys. J. R. Astron. Soc. 52:13-23.

Cogne, J. P., 1987. Paleomagnetic direction obtained by strain removal in the Pyrenean Permian redbeds at the "Col du Somfort" (France). Earth Planet. Sci. Lett., 85:162-172.

Cogne, J. P., and Perroud, H., 1987. Unstraining paleomagnetic vectors: the current state of the debate. Eos, 72:705-712.
Dimanche, F., and Bartholome, P., 1976. The alteration of ilmenite in sediments. Miner. Sci. Eng., 8:187-200.

Facer, R. A., 1983. Folding, strain, and Graham's fold test in paleomagnetic investigations. Geophys. J. R. Astron. Soc., 72:165-171.

Haggerty, S. E., 1976. Opaque mineral oxides in terrestrial igneous rocks. In Rumble, D. (Ed.), Oxide Minerals. Short Course Notes (Mineralogical Society of America), 3:101-277.

Hobbs, B. E., Means, W. D., and Williams, P. F., 1976. An Outline of Structural Geology: New York (Wiley \& Son).

Karlin, R. and Levi, S., 1983. Diagenesis of magnetic minerals in recent hemipelagic sediments. Nature, 303:327-330.

Kent, D. V., and Spariosu, D. J., 1983. High-resolution magnetostratigraphy of Caribbean Plio-Pleistocene deep-sea sediment. Paleogeog. Paleoclim. Paleoecol., 42:47-64.

Mascle, A., Moore, J. C., 1988. Proc. ODP, Init. Repts., 110: College Station, TX (Ocean Drilling Program).

Morad, S., and Aldahan, A. A., 1986. Alteration of Fe-Ti oxides in sedimentary rocks. Geol. Soc. Am. Bull., 97:567-578.

Niitsuma, N., 1981. Paleomagnetic results, Middle America Trench off Mexico, Deep Sea Drilling Project Leg 66. In Watkins, J. S., Moore, J. C., et al., Init. Repts. DSDP, 66: Washington (U.S. Govt. Printing Office), $737-770$.

Niitsuma, N. 1986. Paleomagnetic results, Nankai Trough and Japan Trench, Deep Sea Drilling Project Leg 87. In Kagami, H., Karig, D. E., Coulbourn, W. T., et al., Init. Repts. DSDP, 87: Washington (U.S. Govt. Printing Office), 757-786. 
Ozima, M. 1980., Effects of a plastic deformation on the remanent magnetization of a Cu-Co alloy. Earth Planet Sci. Lett., 47:121123.

Pluijm van der, B. A., 1987. Grain scale deformation and the fold testevaluation of syn-folding remagnetization. Geophys. Res. Lett., 14: 155-157.
Wilson D. S., 1984. Paleomagnetic results from deep sea drilling project Leg 78A. In Biju-Duval, B., Moore, J. C., et al., Init. Repts. DSDP, 78A: Washington (U.S. Govt. Printing Office), 583-591.

Date of initial receipt: 4 January 1988 Date of acceptance: 14 February 1989 Ms 110B-155 
A

NRM intensity $(\mathrm{mA} / \mathrm{m})$

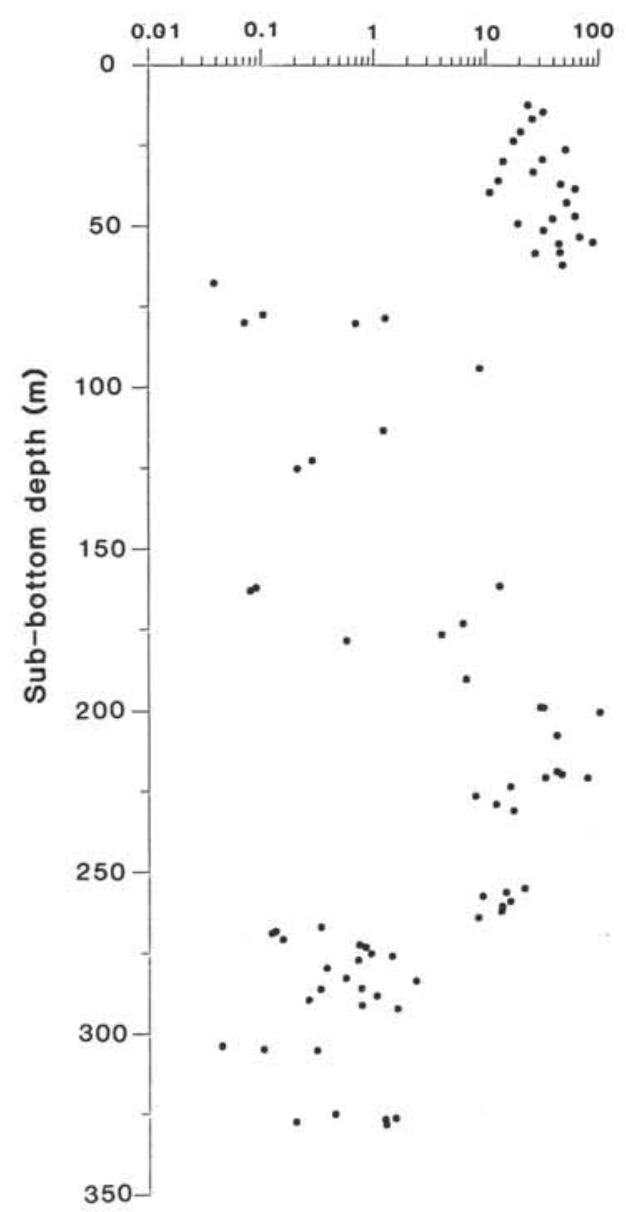

\section{Volume}

susceptibility $\left(\times 10^{-5}\right)$

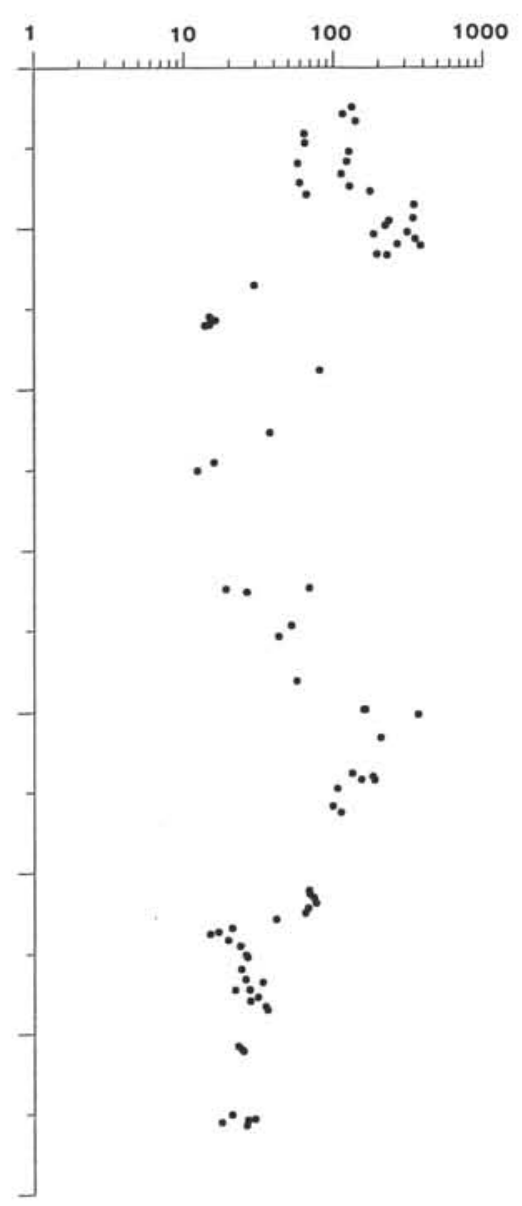

$\operatorname{MDF}(\mathrm{mT})$

Age

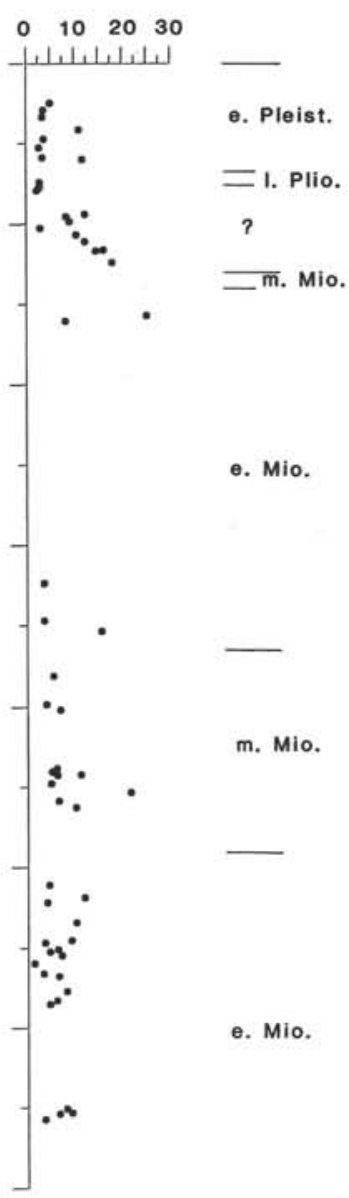

Figure 7. NRM intensity, volume susceptibility, and median destructive field data for A. Hole 673B and B. Hole 674A. Age is based on bioand lithostratigraphy. 
B

NRM intensity $(\mathrm{mA} / \mathrm{m})$

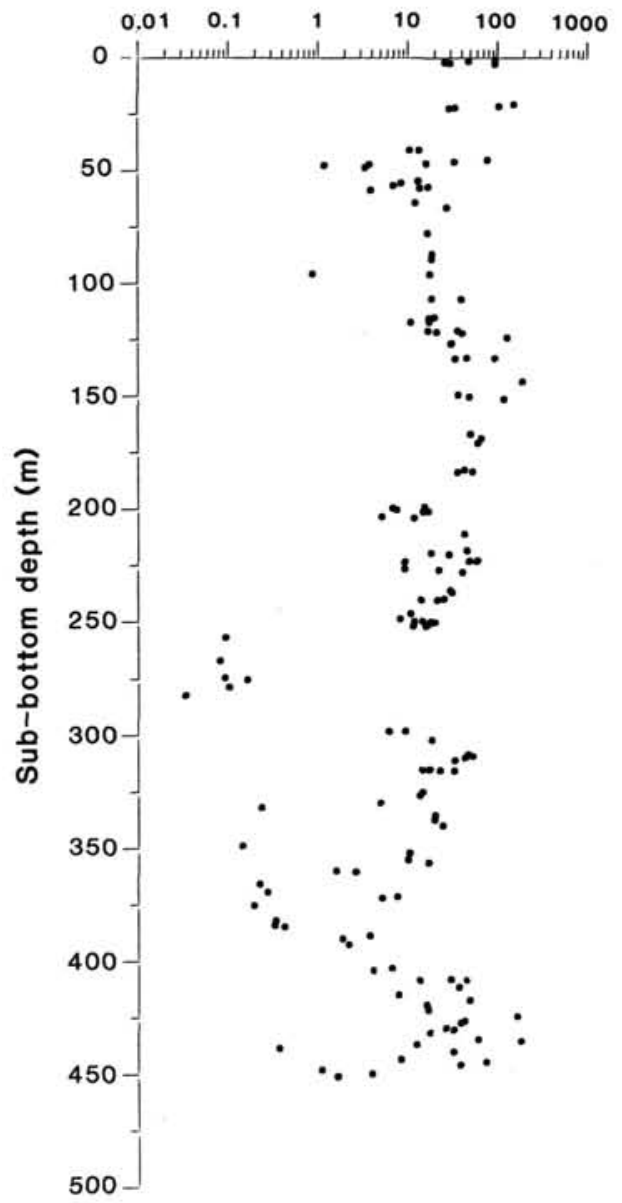

\section{Volume}

susceptibility $\left(\times 10^{-5}\right)$

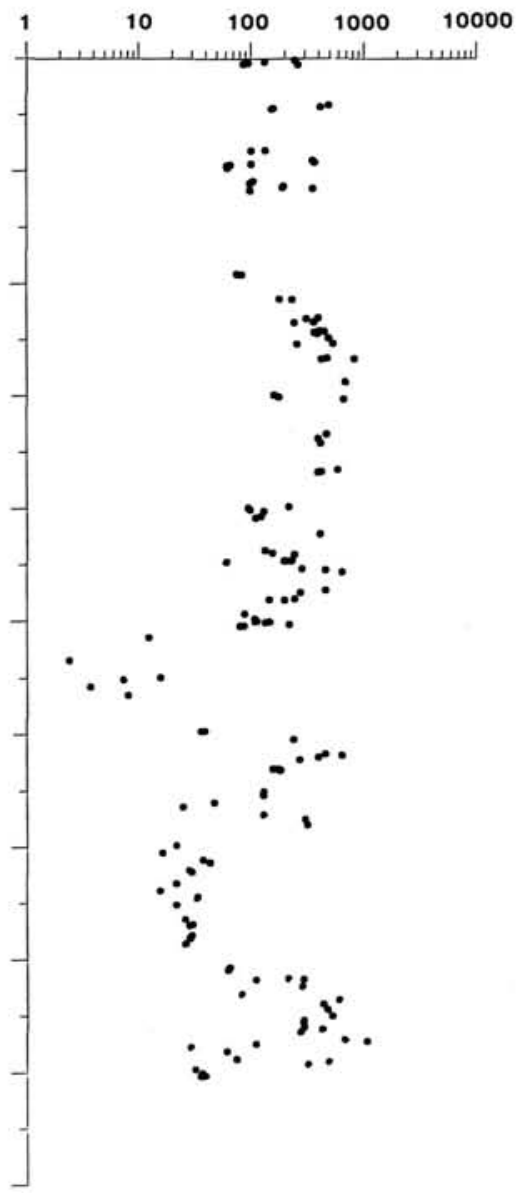

MDF (mT) Age

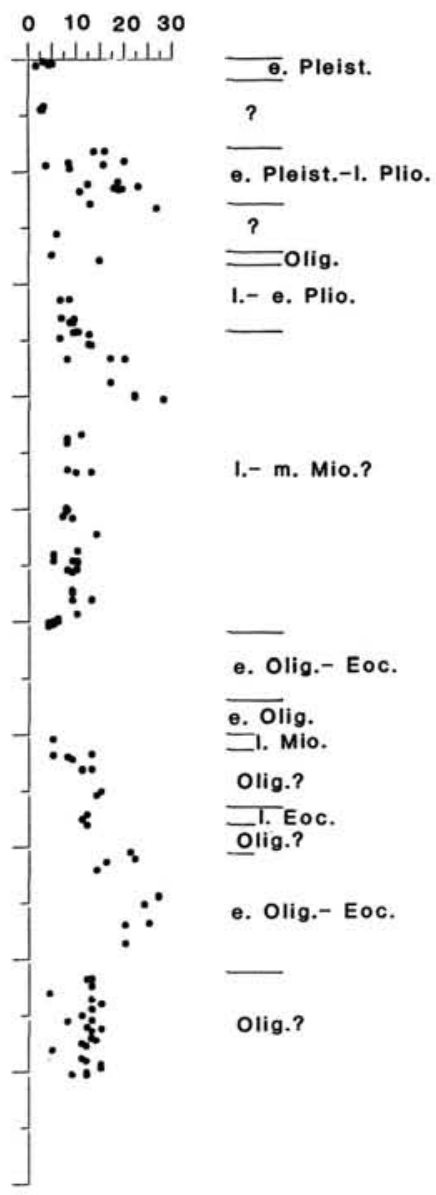

Figure 7 (continued). 


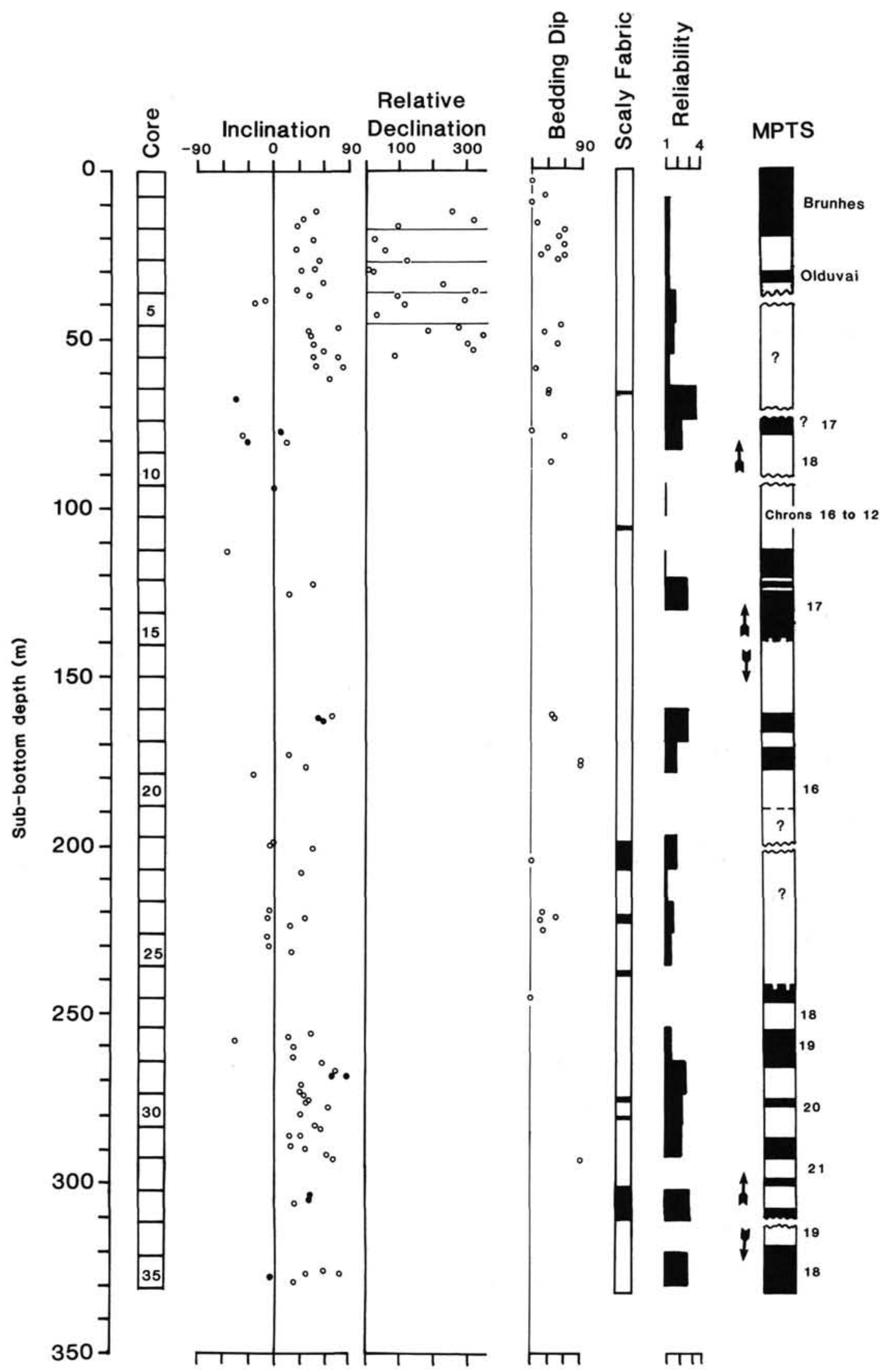

Figure 8. Directional remanence and structural (bedding dip, scaly fabric occurrance) data for Hole 673B. Filled circles are NRM values. No polarity interpretation has been attempted. The magnetic polarity time scale is that expected based on the biostratigraphy. Arrows indicate younging direction. Overturned beds have the MPTS polarity reversed to signify "expected polarity." 


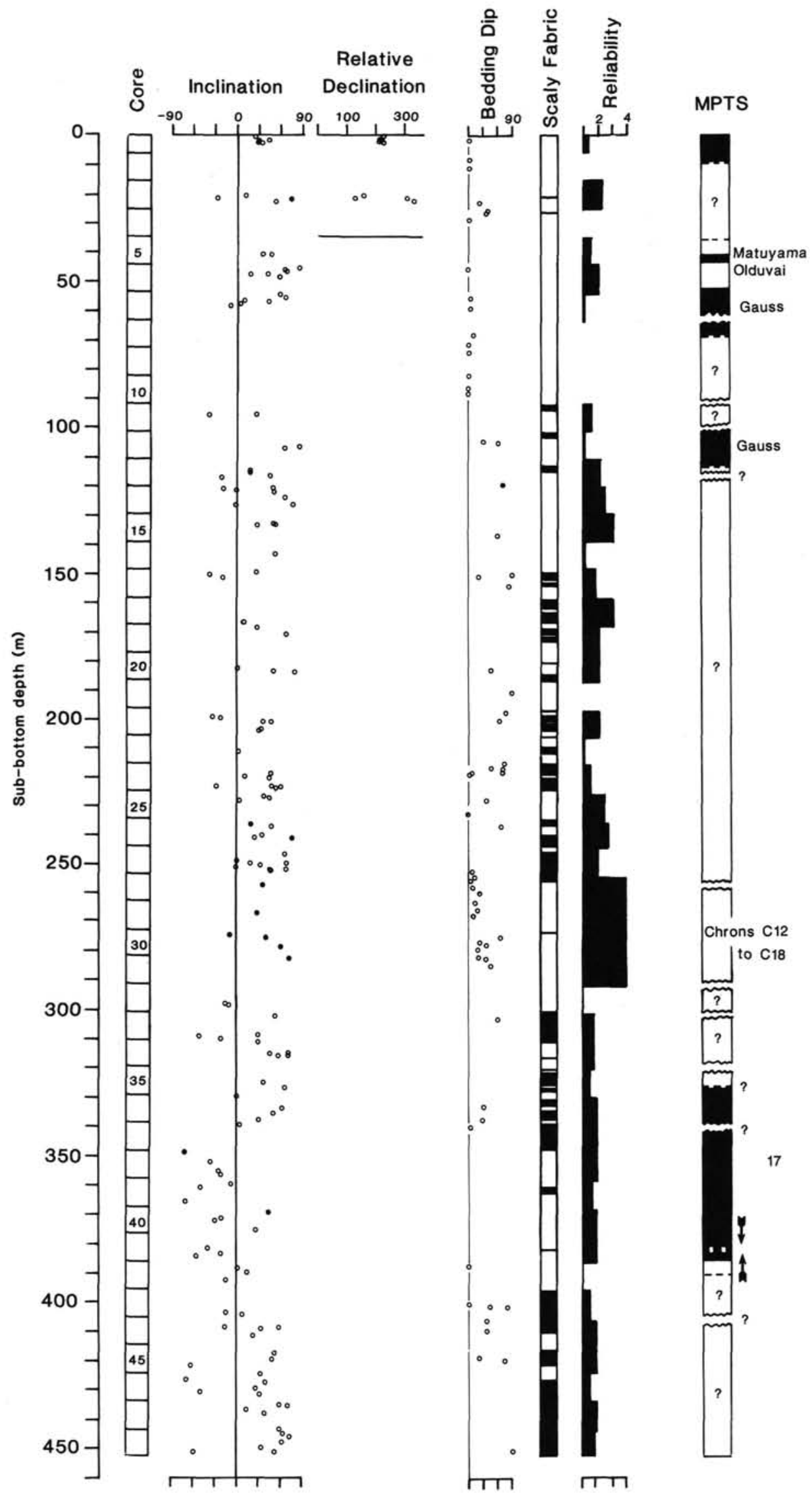

Figure 9. Remanence and structural data for Hole 674A (conventions as in Fig. 8). No polarity interpretation has been attempted. 